\title{
Institutional Outcomes Should Be a Determinant in Decision to Perform Laparoscopic Proctectomies for Rectal Cancer
}

Asya Ofshteyn ${ }^{1}$, Allson B. Weaver ${ }^{1}$, Justin T. Brady ${ }^{1}$, Jay Idrees ${ }^{2}$, Wendy M. Coronado ${ }^{1}$, Scott R. Steele ${ }^{3}$ , Harry Reynolds ${ }^{4,1}$, Emily Steinhagen ${ }^{1}$, Sharon L. Stein ${ }^{5}$

1. Surgery, University Hospitals Cleveland Medical Center / University Hospitals Research in Surgical Outcomes \& Effectiveness Center (UH-RISES), Cleveland, USA 2. General Surgery, University Hospitals Cleveland Medical Center / University Hospitals Research in Surgical Outcomes \& Effectiveness Center (UH-RISES), Cleveland, USA 3. Colorectal Surgery, Cleveland Clinic, Cleveland, USA 4. Surgery, Harney District Hospital, Burns, USA 5. Colorectal Surgery, University Hospitals Cleveland Medical Center / University Hospitals Research in Surgical Outcomes \& Effectiveness Center (UH-RISES), Cleveland, USA

Corresponding author: Asya Ofshteyn, asya.ru@gmail.com

\section{Abstract}

\section{Purpose}

Minimally invasive rectal cancer (RC) resection has become common, despite recent high-profile trials failing to show non-inferiority to open proctectomy. We hypothesized that at a high-volume center, laparoscopic resection may have superior outcomes compared to those seen in ALaCaRT and ACOSOG Z6051.

\section{Methods}

Retrospective review of patients undergoing laparoscopic proctectomy from 2007 to 2015 for RC was performed at a high-volume center. Primary outcome was successful resection defined by negative circumferential resection margin (CRM) and distal margin (DM), and complete total mesorectal excision (TME).

\section{Results}

A total of 89 patients were included. Of 33 patients with TME grading, 31 (93.9\%) had complete/near complete TME, and 29 (87.9\%) had a "successful resection" compared with $81.7 \%$ in ACOSOG and $82 \%$ in ALaCART trials using same criteria. CRM was $\geqslant 1 \mathrm{~mm}$ in 87 (97.8\%) of patients. Mean DM was $3.8 \mathrm{~cm}$; $97.8 \%$ of patients had negative DM.

\section{Conclusion}

Received 02/20/2020 Review began 02/27/2020 Review ended 04/09/2020 Published 04/14/2020

○ Copyright 2020 Ofshteyn et al. This is an open access article distributed under the terms of the Creative Commons Attribution License CC-BY 4.0., which permits unrestricted use, distribution, and reproduction in any medium, provided the original author and source are credited.
High-volume centers can achieve similar high quality RC outcomes to those demonstrated in recent trials. Institutional outcomes should determine optimal surgical technique.

Categories: General Surgery

Keywords: laparoscopic, proctectomy, institutional outcome, rectal cancer, minimally invasive surgery

\section{Introduction}

The goal of surgical resection for rectal cancer is to optimize cancer-free survival and lower the risk of both local and distant recurrence. Due to the lack of longitudinal data, much of the current surgical research has focused on early outcomes including intactness of the mesorectum, and negative circumferential and distal margins [1-9]. There is an ongoing debate regarding the optimal operative approach for management of resectable rectal cancer. It is uncertain whether minimally invasive surgery (MIS) provides equivalent shortterm and/or long-term outcomes for these patients in comparison to traditional open resection.

The CLASSIC trial found that patients undergoing laparoscopic proctectomy had a higher rate of positive circumferential margins compared to open surgery [3]. However, follow-up data failed to demonstrate an oncologic difference in long-term outcomes [10]. ACOSOG Z6051 and ALaCaRT trials failed to demonstrate non-inferiority of short-term outcomes for MIS proctectomy compared to open resection [6,7]. On recently published two-year follow-up results, both studies did not demonstrate significant differences in rates of disease-free survival or recurrence between laparoscopic and open approaches, though estimates of treatment effect in ALaCaRT favored open over laparoscopic approach [11,12]. These results have amplified concerns regarding oncologic safety of MIS approaches for rectal cancer.

High hospital volume, defined as more than 25 laparoscopic proctectomies/year, has been associated with 
better outcomes in rectal cancer [13]. It is therefore reasonable to expect that oncologic safety following laparoscopic proctectomy may vary based on institutional experience. While the feasibility of laparoscopic approaches for surgical resection of rectal cancer has been demonstrated in the setting of randomized trials, institutional level studies evaluating the feasibility, safety and efficacy of laparoscopic proctectomies are limited.

Our aim was to compare our experience with laparoscopic proctectomies to assess outcomes in comparison with data from ACOSOG and ALaCaRT trials. We hypothesized that a high-volume minimally invasive center, where surgeons preferentially select MIS techniques, would have better outcomes following a laparoscopic proctectomy than currently reported in the literature. This would justify a preference for laparoscopic approach in carefully selected patients based on individual center outcomes.

\section{Materials And Methods}

Following Institutional Review Board (IRB) approval, a retrospective review of patients undergoing laparoscopic resection for rectal cancer at University Hospitals Cleveland Medical Center from 2007 to 2015 was performed. Patients who underwent surgery for rectal cancer were identified from the medical record using International Classification of Disease 9th Revision diagnosis code 154.1. Inclusion and exclusion criteria were adopted from the ACOSOG and ALaCaRT trials. Patients were included if they were over 18 years of age, had a primary rectal adenocarcinoma (defined as $<15 \mathrm{~cm}$ from the anal verge by endoscopic or radiologic measurement) diagnosed by histology and were planned to undergo laparoscopic resection. Patients were excluded if they had recurrent disease, were scheduled for a palliative resection, multivisceral resection or intraoperative radiation therapy, if they had clinical stage T4 tumors, stage IV disease or unknown preoperative clinical staging information.

Patient information collected included demographics, comorbidities, use of neoadjuvant and adjuvant chemoradiotherapy, clinical and pathological staging, operative details, complete total mesorectal excision (TME), specimen grade (when available), hospital length of stay and postoperative complications. Patients underwent clinical evaluation including proctoscopy, computed tomography, ultrasound and magnetic resonance imaging as deemed clinically appropriate. The decision for laparoscopic surgery was at surgeon discretion and preference. Study data were collected and managed using a REDCap database hosted at University Hospitals Cleveland Medical Center [14].

\section{Primary and secondary outcomes}

The primary outcome was the composite endpoint of negative distal and circumferential resection margins and TME grade, when available. This was modeled on the ALaCaRT and ACOSOG primary study endpoints. Secondary endpoints included conversion rate and significant intraoperative and postoperative morbidity (Clavien-Dindo class 3-5 complications). This data was then compared to published outcomes for rectal cancer to determine if they matched or exceeded acceptable standards for minimally invasive surgery.

\section{Statistical analysis}

Continuous variables are shown as the mean with standard deviation (SD) or median with interquartile range (IQR) and were compared using two-way Student t-test or Wilcoxon rank sum test where appropriate. Categorical variables are displayed as frequencies with percentages and were compared using Chi-square or Fischer's exact where appropriate. A p-value less than 0.05 was considered significant. Statistical analysis was performed using Stata/SE 14.2 (StataCorp, College Station, TX, USA).

\section{Results}

There were 386 patients who underwent minimally invasive proctectomy between 2007 and 2015 at our institution. In 148 (38.3\%) cases, the proctectomy was performed for malignancy. Of these, 89 (60\%) patients met the inclusion criteria and were included in the analysis. Patients with multi-visceral resection $(n=19)$, recurrent disease $(n=20)$, stage 4 disease $(n=14)$ and intraoperative radiation $(n=6)$ were excluded. Mean age at the time of surgery was 66 years and 54 (60.7\%) patients were male. Nearly $80 \%$ of patients received neoadjuvant chemotherapy and radiation. Table 1 summarizes patient characteristics. 


\section{Cureus}

\begin{tabular}{|c|c|c|c|}
\hline & Current Study & ACOSOG Z6051 & P-value \\
\hline Patients, n & 89 & 242 & \\
\hline Male gender, $\mathrm{n}(\%)$ & $54(60.7)$ & $156(64.5)$ & 0.84 \\
\hline Age, mean (SD) & $66.3(12.9)$ & $57.1(11.5)$ & $<0.0001$ \\
\hline BMI, mean (SD) & $28.4(7.2)$ & $26.4(4.0)$ & 0.002 \\
\hline Planned Operation, n (\%) & & & 0.25 \\
\hline Abdominal perineal resection & $17(19.1)$ & $55(22.7)$ & \\
\hline Low anterior resection & 71 (79.8) & $187(77.3)$ & \\
\hline Total proctocolectomy & 1 (1.1) & & \\
\hline Location of tumor in rectum, $\mathrm{n}(\%)^{\mathrm{a}}$ & & & $<0.001$ \\
\hline High & $13(15.9)$ & $33(13.6)$ & \\
\hline Middle & $49(59.8)$ & $85(35.1)$ & \\
\hline Low & $20(24.4)$ & $124(51.2)$ & \\
\hline Tumor distance from anal verge, mean (SD), cm & $6.8(2.9)$ & $6.1(3.1)$ & 0.07 \\
\hline Preoperative clinical stage, $\mathrm{n}(\%)$ & & & $<0.001$ \\
\hline I & $17(19.1)$ & $2(0.8)$ & \\
\hline II & $32(36)$ & $99(40.9)$ & \\
\hline III & $40(44.9)$ & 141 (58.2) & \\
\hline Preoperative therapy received, $n(\%)$ & & & $<0.001$ \\
\hline Chemotherapy + radiation & $71(79.8)$ & $227(95.0)$ & \\
\hline Radiation alone & $2(2.2)$ & $8(3.3)$ & \\
\hline Chemotherapy & $1(1.1)$ & $4(1.7)$ & \\
\hline Unknown & 0 & 3 & \\
\hline None & $15(17.6)$ & 0 & \\
\hline
\end{tabular}

TABLE 1: Demographics and patient characteristics, current study compared to ACOSOG.

SD: Standard deviation; BMI: Body mass index

a Rectal tumor location was defined as follows: low $-\leq 5 \mathrm{~cm}$ from the anal verge, middle - from $>5$ to $10 \mathrm{~cm}$, and high from $>10$ to $15 \mathrm{~cm}$.

\section{Operative technique}

Surgery was performed laparoscopically in 79 (88.8\%) of the cases. Of the remaining $10(11 \%)$ included cases, eight were robotic-assisted and two cases were hand-assisted laparoscopic resection. Included surgical procedures were low anterior resection (LAR) with anastomosis $(n=60,67 \%)$, abdominoperineal resection (APR) ( $n=23,26 \%)$, Hartmann procedure $(n=5,6 \%)$ and total proctocolectomy $(n=1,1 \%)$. A stoma was created in 87 cases, $30.3 \%$ of which were colostomies. The mean operative time was 326.4 minutes, with a mean estimated blood loss (EBL) of $137.2 \mathrm{~mL}$. Conversion rate was $24.7 \%(n=22 / 89)$. Cases that required conversion were still analyzed as their intended MIS approach. Intraoperative complications occurred in $3.4 \%$ of surgeries.

Short-term complications within 30 days of surgery occurred in $31.5 \%(\mathrm{n}=28)$, most commonly including deep space infection $(n=7,7.9 \%)$, ileus $(n=7,7.9 \%)$, urinary retention $(n=7,7.9 \%)$, surgical site infection ( $n$ $=6,6.7 \%)$ and atrial fibrillation $(n=4,4.5 \%)$. The rate of re-operation was $4.5 \%(n=4)$ and the overall 30 day mortality was $1.1 \%(n=1 / 89)$. Readmission occurred in $12.4 \%$. The clinical outcomes are summarized in Table 2. 


\section{Cureus}

\begin{tabular}{|c|c|c|c|}
\hline & Current Study & ACOSOG & P-Value \\
\hline Surgical Approach, n (\%) & & & $<0.001$ \\
\hline Low Anterior Resection & $3(3.4)$ & $68(35.6)$ & \\
\hline Low Anterior Resection + Coloanal Anastomosis & $57(64.0)$ & $109(57.1)$ & \\
\hline Abdominal Perineal Resection & $23(25.8)$ & $11(5.8)$ & \\
\hline Low Hartmann & $5(5.6)$ & $1(0.4)$ & \\
\hline Total Proctectomy & 0 & $2(1.0)$ & \\
\hline Total Proctocolectomy & $1(1.1)$ & 0 & \\
\hline Surgical Approach & & & $<0.001$ \\
\hline Laparoscopic & $79(88.8)$ & $165(68.8)$ & \\
\hline Hand assisted & $2(2.3)$ & $41(17.1)$ & \\
\hline Robotic assisted & $8(9.1)$ & $34(14.2)$ & \\
\hline Ostomy Created & & & 0.73 \\
\hline Colostomy & $27(30.3)$ & $63(26.3)$ & \\
\hline lleostomy & $60(67.4)$ & $171(71.3)$ & \\
\hline Sphincter preservation planned before operation, $\mathrm{n}(\%)$ & $68(68)$. & $191(79.6)$ & 0.62 \\
\hline Margins examined by frozen, $\mathrm{n}(\%)$ & $10(11.2)$ & $51(21.3)$ & 0.04 \\
\hline Open to close operative time, mean (SD), min & $326.4(100.2)$ & $266.2(101.9)$ & $<0.0001$ \\
\hline Total EBL, mean (SD), mL & $137.2(139.8)$ & $256.1(305.8)$ & 0.0005 \\
\hline Conversion, n (\%) & $22(24.7)$ & $27(11.3)$ & 0.001 \\
\hline Complications (intraoperative and postoperative), $\mathrm{n}(\%)$ & $33(37.1)$ & $137(57.1)$ & 0.001 \\
\hline Total intraoperative complications, $\mathrm{n}(\%)$ & $3(3.4)$ & $26(10.8)$ & 0.047 \\
\hline Rectum & 1 (1.1) & $10(4.2)$ & \\
\hline Colon & 0 & $3(1.3)$ & \\
\hline Small bowel & 0 & 0 & \\
\hline Ureter & 0 & $1(0.4)$ & \\
\hline Bladder & 0 & $1(0.4)$ & \\
\hline Spleen & 0 & 0 & \\
\hline Hemorrhage/bleeding associated with surgery & 0 & $8(3.3)$ & \\
\hline Other & $2(2.2)$ & $5(2.1)$ & \\
\hline Maximum grade of postoperative complications, Clavien-Dindo, $n(\%)$ & $28(31.5)$ & $129(53.8)$ & $<0.001$ \\
\hline 3 & $7(7.9)$ & $46(19.2)$ & \\
\hline 4 & 0 & $6(2.5)$ & 0.06 \\
\hline 5 & $3(3.4)$ & $2(0.8)$ & \\
\hline Anastomotic leak during postoperative period, $\mathrm{n}(\%)$ & 0 & $5(2.1)$ & 0.17 \\
\hline 30-day mortality, n (\%) & $3(3.4)$ & $2(0.8)$ & 0.09 \\
\hline Rehospitalization (within 30 days of discharge), $n$ (\%) & $11(12.4)$ & $8(3.3)$ & 0.002 \\
\hline Reoperation, $\mathrm{n}(\%)$ & $7(7.9)$ & $12(5.0)$ & 0.32 \\
\hline
\end{tabular}




\section{Cureus}

TABLE 2: Operative details and outcomes, current study compared to ACOSOG.

EBL: Estimated blood loss.

\section{Technical and oncologic success}

A clear circumferential margin was obtained in 87 (97.8\%) cases. A negative distal margin was achieved in 87 (97.8\%) cases. Completeness of TME based on pathologic assessment was not standardized until 2012; therefore, TME completeness was only available for 33 cases. The 33-patient cohort was statistically compared to our larger 89-patient group and was found to be clinically similar in the relevant demographic, patient and tumor characteristic, operative detail and outcome parameters. TME was graded as complete/near complete in 31 (93.9\%) of the cases (29 complete, four nearly complete). The mean number of lymph nodes examined was 18.3 (SD 5). Overall, $87.9 \%$ of cases were considered "pathologically successful" based on negative circumferential and distal margins and complete/near complete TME. The majority of tumors (69.7\%) were well or moderately differentiated. These results are summarized in Table 3.

\begin{tabular}{|c|c|c|c|}
\hline & Current Study & ACOSOG Z6051 & P-value \\
\hline Circumferential Resection Margin, $\mathrm{n}(\%)^{\mathrm{a}}$ & & & $<0.001$ \\
\hline Negative CRM & $87(97.8)$ & $211(87.9)$ & \\
\hline Positive & 1 & 29 & \\
\hline Distance to nearest radial margin, mean (SD), mm & $11(8.4)$ & $12.8(11.2)$ & 0.28 \\
\hline Negative distal margin, $\mathrm{n}(\%)$ & $87(97.8)$ & 236 (98.3) & 1.0 \\
\hline Distance to distal margin, mean (SD), cm & $3.8(3.7)$ & $3.2(2.6)$ & 0.1 \\
\hline Total Mesorectal Excision, $\mathrm{n}(\%)$ & $(n=33)$ & $(n=240)$ & 0.14 \\
\hline Complete & $29(87.9 \%)$ & $175(72.9)$ & \\
\hline Nearly complete & $4(12.1 \%)$ & 46 (19.2) & \\
\hline Incomplete & 0 & $19(7.9)$ & \\
\hline Number of lymph nodes examined, mean (SD) & $18.3(5.0)$ & $17.9(10.1)$ & 0.72 \\
\hline Successful resection ${ }^{b}$ & $87.9 \%$ & $81.7 \%$ & 0.47 \\
\hline Total length of resected specimen, mean (SD), cm & 27.7 (12.6) & 28.9 (10.8) & 0.36 \\
\hline Stage, $n(\%)$ & & 239 & 0.16 \\
\hline 0 & $13(14.6)$ & $55(23)$ & \\
\hline I & $40(44.9)$ & $76(31.8)$ & \\
\hline II & $18(20.2)$ & 47 (19.6) & \\
\hline III & $18(20.2)$ & $60(33.5)$ & \\
\hline IV & 0 & $1(0.4)$ & \\
\hline Tumor size, mean (SD), cm & $2.1(1.5)$ & $2.3(1.8)$ & 0.37 \\
\hline
\end{tabular}

\section{TABLE 3: Oncologic outcomes, current study compared to ACOSOG.}

CRM: Circumferential resection margin; TME: Total mesorectal excision.

${ }^{\text {a }}$ Circumferential resection margin for present study defined as negative if $>1 \mathrm{~mm}$, for ACOSOG study as $>1 \mathrm{~mm}$.

${ }^{b}$ For 33 patients in current study with TME grade listed. Defined as complete TME, negative circumferential and distal margins.

\section{Outcomes compared to published literature}




\section{Cureus}

We compared our data to historical data provided from the ACOSOG and ALaCaRT trials. Demographic data between our study and the ACOSOG and ALaCaRT studies was generally similar, with a few noticeable differences (Table 4). In our experience, the location of the tumor was slightly higher in the rectum, with only $24.4 \%$ being low compared to $51.2 \%$ for the ACOSOG and $35 \%$ for the ALaCaRT. We also had fewer patients who received preoperative chemoradiation (79.8\%) compared to the $95 \%$ of ACOSOG, but more than the $50 \%$ of ALaCaRT participants who received preoperative radiation.

\begin{tabular}{|c|c|c|c|}
\hline & Current Study & ALaCaRT & P-value \\
\hline Male gender, n (\%) & $54(60.7)$ & $160(67)$ & 0.3 \\
\hline Age, median (IQR), y & $68(57-750)$ & $65(56-74)$ & \\
\hline BMI, median (IQR) & $28.4(24.1-33.7)$ & $27(24-30)$ & \\
\hline $\mathrm{BMI}>30, \mathrm{n}(\%)$ & $45(60)$ & $56(24)$ & $<0.0001$ \\
\hline Location of tumor in rectum, $\mathrm{n}(\%)$ & & & 0.04 \\
\hline High & $13(15.9)$ & $53(22)$ & \\
\hline Middle & $49(59.8)$ & $103(43)$ & \\
\hline Low & $20(24.4)$ & $82(35)$ & \\
\hline Tumor stage, $\mathrm{n}(\%)$ & & & 0.13 \\
\hline T1 & $1(1.0)$ & $18(8)$ & \\
\hline T2 & 21 (23.6) & $68(29)$ & \\
\hline T3 & $67(75.3)$ & $151(63)$ & \\
\hline Nodal status, $\mathrm{n}(\%)$ & & & 0.001 \\
\hline No & $48(53.9)$ & 107 (45) & \\
\hline N1 & $39(43.8)$ & $92(39)$ & \\
\hline N2 & $2(2.3)$ & $37(16)$ & \\
\hline Distant metastases, $\mathrm{n}(\%)$ & 0 & $10(4)$ & 0.007 \\
\hline Preoperative radiotherapy, $\mathrm{n}(\%)$ & $73(82.0)$ & $119(50)$ & $<0.001$ \\
\hline
\end{tabular}

TABLE 4: Demographics and patient characteristics, current study compared to ALaCaRT.

IQR: Interquartile range.

Operative data varied between our study and ACOSOG. While our operative time was significantly longer (326.4 min vs. $266.2 \mathrm{~min}, \mathrm{p}<0.0001$ ), other intraoperative parameters were favorable including lower EBL (137.2 vs. $256.1, \mathrm{p}=.0005)$, fewer intraoperative complications ( $37.1 \%$ vs. $57.1 \%, \mathrm{p}=.047$ ), and lower rate of postoperative complications ( $31.5 \%$ vs. $53.8 \%, \mathrm{p}<.001)$. Clinically, a higher proportion of our patients underwent APR $(25.8 \%$ vs. $5.8 \% \mathrm{p}<0.001)$ and our study had a lower proportion of hand-assisted or robotic assisted procedures $(11.4 \%$ vs. $31.3 \% \mathrm{p}<0.001)$ than the ACOSOG trial. Compared to ACOSOG, conversion rate $(24.7 \%$ vs. $11 \%, \mathrm{p}=0.001)$ and 30 -day readmission rates $(12.4 \%$ vs. $3.3 \%, \mathrm{p}=0.002)$ were higher in our experience (Table 5). 


\section{Cureus}

\begin{tabular}{|c|c|c|c|}
\hline & Current Study & ALaCaRT & P-value \\
\hline Surgical Approach, n (\%) & & & $<0.001$ \\
\hline Low Anterior Resection & $3(3.4)$ & $143(60)$ & \\
\hline Low Anterior Resection + coloanal anastomosis & $57(64.0)$ & $69(29)$ & \\
\hline Abdominal Perineal Resection & $23(25.8)$ & $25(11)$ & \\
\hline Low Hartmann & $5(5.6)$ & 0 & \\
\hline Total Proctectomy & 0 & 0 & \\
\hline Total proctocolectomy & $1(1.1)$ & 0 & \\
\hline Ostomy Created, n (\%) & & & 0.003 \\
\hline Colostomy & $27(30.3)$ & 30 (13) & \\
\hline lleostomy & $60(67.4)$ & $162(68)$ & \\
\hline Operative time, median (IQR), min & $310(253-380)$ & $210(163-253)$ & \\
\hline Total EBL, median (IQR), mL & $100(22.5-200)$ & $100(50-200)$ & \\
\hline Conversion, n (\%) & $22(24.7)$ & 21 (9) & $<0.001$ \\
\hline
\end{tabular}

TABLE 5: Operative details and outcomes, current study compared to AlaCaRT.

IQR: Interquartile range; EBL: Estimated blood loss.

Operative data for our study was similar to ALaCaRT data. A lower proportion of our patients underwent LAR ( $67.4 \%$ vs. $89 \%, p<0.001)$, and our operative times were comparatively longer (310 vs. 210 minutes). EBL was similar between the studies. The rate of conversion to open surgery was statistically higher in our study $(24.7 \%$ vs. $9 \%, \mathrm{p}<0.001)$. Other outcome measures in ALaCART were reported as medians and thus comparisons could not be performed (Table 6). 


\section{Cureus}

\begin{tabular}{|c|c|c|c|}
\hline & Current Study & ALaCaRT & P-value \\
\hline Radial margin, n (\%) & & & 0.049 \\
\hline Positive (<1 mm) & $1(1.1)$ & $16(6.7)$ & \\
\hline Negative (> or equal to $1 \mathrm{~mm}$ ) & $87(98.9)$ & $222(93)$ & \\
\hline Negative distal margin >1 mm, n (\%) & $87(97.8)$ & $236(99)$ & 0.3 \\
\hline Total Mesorectal Excision, $\mathrm{n}(\%)$ & & & 0.66 \\
\hline Complete & $29(87.9)$ & $206(87)$ & \\
\hline Nearly complete & $4(12.1)$ & 24 (10) & \\
\hline Incomplete & 0 & $8(3)$ & \\
\hline Successful resection, $n(\%)$ & $29(87.9)$ & $194(82)$ & 0.47 \\
\hline lumor stage, $n$ (\%) & & & 0.22 \\
\hline T0 (or no residual tumor) & $12(13.5)$ & $33(14)$ & \\
\hline 11 & $13(14.6)$ & $23(10)$ & \\
\hline T2 & $31(34.8)$ & $67(28)$ & \\
\hline T3 & $31(34.8)$ & $104(44)$ & \\
\hline T4 & $1(1.1)$ & $11(5)$ & \\
\hline Tumor size, median (IQR), mm & $20(10-30)$ & $30(20-40)$ & \\
\hline Total length of resected specimen, median (IQR), mm & $260(215-313)$ & $260(205-310)$ & \\
\hline
\end{tabular}

\section{TABLE 6: Oncologic outcomes, current study compared to ALaCaRT.}

Overall, our pathologic outcomes were favorable when compared to ACOSOG results. Our CRM margin was negative in $97.8 \%$ compared to the $87.9 \%$ of ACOSOG $(\mathrm{p}<.001)$. The overall "success rate" was higher in our study compared to in ACOSOG ( $87.9 \%$ vs. $81.7 \%, \mathrm{p}=0.47$ ), although this value did not reach statistical significance. Lymph node harvests were similar between studies.

Pathologic outcomes between our study and ALaCaRT were similar for most measures, including negative distal margin, completeness of TME, and percent successful resection. Our radial margin was negative in $98.9 \%$ of patients, compared to $93 \%(p=0.047)$ in the ALaCaRT data. The tumors in the two studies had similar sizes and histologic grades, although a greater proportion of patients in our study had node negative disease (N0 79.8\% vs. $62 \%$, p < 0.01 ).

\section{Discussion}

This study demonstrates that at a high-volume minimally invasive center, MIS proctectomy for surgical resection of rectal cancer can be performed safely with excellent short-term oncologic outcomes. While much of the current debate regarding the use of MIS for resection of rectal cancer is focused on the feasibility of technique, we believe that the preference for minimally invasive approaches should be based on institutional and surgeon data.

To this point, we found that the selection of a minimally invasive approach was justified in our experience as we were able to achieve a high overall negative CRM margin in $98 \%$ of the cases and an overall success rate of $88 \%$ in the 33-patient cohort with reported TME grade. While this success rate surpasses $81.7 \%$ in ACOSOG and $82 \%$ in ALaCART, it is comparable to the open surgical success seen in ACOSOG (86.9\%) and ALaCART (89\%). We have demonstrated that individual centers can achieve results that compare favorably to the outcomes of MIS approaches and are similar to results of open approaches reported in ACOSOG and ALaCaRT clinical trials. These results emphasize the importance of institutional level evaluation of outcomes to guide decision making regarding the appropriate surgical approach. We believe that our good outcomes can be attributable to careful patient selection of best candidates for surgery and high volume of experience of each surgeon practicing in our institution at the time. 
The findings from our study are consistent with the current literature and adds to the growing evidence in favor of the use of laparoscopic approaches. Arezzo et al. performed a systematic review and meta-analysis, evaluating the outcomes of laparoscopic approaches compared to open resection [9]. In their meta-analysis they included results from clinical trials and retrospective studies and found that the incidence of CRM margin involvement was $7.9 \%$ after laparoscopic resection compared to $6.9 \%$ in the open resection group with an overall relative risk of 1.0 (95\% CI: 0.73-1.35). The authors concluded that the oncological adequacy of laparoscopic proctectomy was equivalent to open resection. Another, more recent meta-analysis by Acuna et al. demonstrated non-inferiority of laparoscopic surgery compared to open in terms of quality of surgical resection outcomes, including positive CRM, incomplete TME and positive distal resection margin [15].

In our experience, the CRM margin involvement was even lower than demonstrated by Arezzo et al. (2.2\%), indicating that there can be significant variability in outcomes and practice patterns among institutions. While many studies, such as ACOSOG and ALaCaRT, compare data to equivalent patients who undergo open surgery, we were unable to perform such comparison. At our institution, surgeons have historically preferred minimally invasive techniques for rectal cancer. In general, the open approach was reserved for more advanced tumors, hostile abdomens, or patients with severe medical comorbidities complicating minimally invasive techniques. Patients who are not selected for minimally invasive surgery are therefore not equivalent, with increased concerns for threatened margin, advanced tumors, or other contraindications to minimally invasive surgery.

There are several limitations to this study. Standardization of surgeon and pathologist oncologic evaluation over time presents complications in normalizing the data. We were only able to report completeness of TME in under half of our procedures. Therefore, we were only able to report "successful resection" in a proportion of our patients. It may be inaccurate to extrapolate high rates of complete TME to our earlier patients. The lack of uniformity in oncologic outcomes between ACOSOG and ALaCaRT complicates direct comparison. Examples of this include the use of means versus medians, and distal resection margin of $1 \mathrm{~mm}$ versus greater than $1 \mathrm{~mm}$. Additionally, our study cohort is limited by its sample size, which restricts our ability to demonstrate statistical significance in some cases. Lastly, there were differences in tumor demographics between our study and ACOSOG and ALaCaRT. A greater proportion of our tumors were higher in the rectum, which may affect rates of "successful" surgery. Additionally, our conversion and APR rates were higher than the trial populations. Surgeon specific and institutional specific data should not be extrapolated to other institutions, and surgeons need to know their own data to make decisions about the best possible approach in each surgeon's hands.

Decisions regarding choice of surgical technique should be based on data obtained from the institution and surgeon, rather than based on technique. Similar to baseball, one would not give a bat a batting average, the batting average would be attributed to the batter, using their bat of choice. Comparably, we hope that the debate regarding the use of minimally invasive surgery will focus on surgeon and institutional outcomes, rather than global evaluation of the techniques.

\section{Conclusions}

Minimally invasive proctectomy for the surgical resection of rectal cancer can be performed safely, but the decision for the selection of minimally invasive approach should be based on the institutional evaluation of outcomes for optimal results.

\section{Additional Information \\ Disclosures}

Human subjects: Consent was obtained by all participants in this study. University Hospitals Cleveland Medical Center Institutional Review Board issued approval 11-15-21C. The IRB reviewed and approved this submission. $\mathbf{X}$ Per Federal regulation, changes MAY NOT be made to any element of the current research without prior IRB approval, except to eliminate an immediate and apparent hazard to subjects enrolled in the study. $\mathbf{X}$ Per Federal regulation, the research may not continue beyond the Approval End date. You must submit a continuing review form 6-8 weeks before this Approval End date in order to maintain IRB approval. Failure to maintain IRB approval is human subjects non-compliance. Please note that even if your study falls into a category that does not require an Approval End date, the institution may require a yearly "checkin" to confirm the status of the study. . Animal subjects: All authors have confirmed that this study did not involve animal subjects or tissue. Conflicts of interest: In compliance with the ICMJE uniform disclosure form, all authors declare the following: Payment/services info: All authors have declared that no financial support was received from any organization for the submitted work. Financial relationships: Sharon L. Stein declare(s) a grant from 11 Health and Technologies Limited. This is a grant for a different research project. Sharon L. Stein declare(s) personal fees from Merck \& Co. Speaker for Merck \& Co. Scott Steele declare(s) personal fees from Medtronic. Dr. Steele has taught courses on laparoscopic colectomy for Medtronic and Ethicon. Scott Steele. declare(s) personal fees from Ethicon. Dr. Steele has taught courses on laparoscopic colectomy for Medtronic and Ethicon. Other relationships: All authors have declared that there are no other relationships or activities that could appear to have influenced the submitted work. 


\section{References}

1. Colorectal cancer facts \& figures 2014-2016. (2014). Accessed: April 14, 2020: https://www.cancer.org/research/cancer-facts-statistics/colorectal-cancer-facts-figures.html.

2. Veldkamp R, Kuhry E, Hop WCJ, et al.: Laparoscopic surgery versus open surgery for colon cancer: shortterm outcomes of a randomised trial. Lancet Oncol. 2005, 6:477-484. 10.1016/S1470-2045(05)70221-7

3. Guillou PJ, Quirke P, Thorpe H, et al.: Short-term endpoints of conventional versus laparoscopic-assisted surgery in patients with colorectal cancer (MRC CLASICC trial): multicentre, randomised controlled trial. Lancet. 2005, 365:1718-1726. 10.1016/S0140-6736(05)66545-2

4. Green BL, Marshall HC, Collinson F, Quirke P, Guillou P, Jayne DG, Brown JM: Long-term follow-up of the Medical Research Council CLASICC trial of conventional versus laparoscopically assisted resection in colorectal cancer. Br J Surg. 2013, 100:75-82. 10.1002/bjs.8945

5. Jeong S-Y, Park JW, Nam BH, et al.: Open versus laparoscopic surgery for mid-rectal or low-rectal cancer after neoadjuvant chemoradiotherapy (COREAN trial): survival outcomes of an open-label, non-inferiority, randomised controlled trial. Lancet Oncol. 2014, 15:767-774. 10.1016/S1470-2045(14)70205-0

6. Stevenson ARL, Solomon MJ, Lumley JW, et al.: Effect of laparoscopic-assisted resection vs open resection on pathological outcomes in rectal cancer: the ALaCaRT randomized clinical trial. JAMA. 2015, 314:13561363. 10.1001/jama.2015.12009

7. Fleshman J, Branda M, Sargent DJ, et al.: Effect of laparoscopic-assisted resection vs open resection of stage II or III rectal cancer on pathologic outcomes: the ACOSOG Z6051 randomized clinical trial. JAMA. 2015, 314:1346-1355. 10.1001/jama.2015.10529

8. Bonjer HJ, Deijen CL, Abis GA, et al.: A randomized trial of laparoscopic versus open surgery for rectal cancer. N Engl J Med. 2015, 372:1324-1332. 10.1056/NEJMoa1414882

9. Arezzo A, Passera R, Salvai A, Arolfo S, Allaix ME, Schwarzer G, Morino M: Laparoscopy for rectal cancer is oncologically adequate: a systematic review and meta-analysis of the literature. Surg Endosc. 2015, 29:334348. 10.1007/s00464-014-3686-4

10. Jayne DG, Thorpe HC, Copeland J, Quirke P, Brown JM, Guillou PJ: Five-year follow-up of the Medical Research Council CLASICC trial of laparoscopically assisted versus open surgery for colorectal cancer. Br J Surg. 2010, 97:1638-1645. 10.1002/bjs.7160

11. Fleshman J, Branda ME, Sargent DJ, et al.: Disease-free survival and local recurrence for laparoscopic resection compared with open resection of stage II to III rectal cancer: follow-up results of the ACOSOG Z6051 randomized controlled trial. Ann Surg. 2019, 269:589-595. 10.1097/SLA.0000000000003002

12. Stevenson ARL, Solomon MJ, Brown CSB, et al.: Disease-free survival and local recurrence after laparoscopic-assisted resection or open resection for rectal cancer: the Australasian laparoscopic cancer of the rectum randomized clinical trial. Ann Surg. 2019, 269:596-602. 10.1097/SLA.0000000000003021

13. Aquina CT, Probst CP, Becerra AZ, et al.: High volume improves outcomes: the argument for centralization of rectal cancer surgery. Surgery. 2016, 159:736-748. 10.1016/j.surg.2015.09.021

14. Harris PA, Taylor R, Thielke R, Payne J, Gonzalez N, Conde JG: Research electronic data capture (REDCap)-a metadata-driven methodology and workflow process for providing translational research informatics support. J Biomed Inform. 2009, 42:377-381. 10.1016/j.jbi.2008.08.010

15. Acuna SA, Chesney TR, Amarasekera ST, Baxter NN: Defining non-inferiority margins for quality of surgical resection for rectal cancer: a Delphi consensus study. Ann Surg Oncol. 2018, 25:3171-3178. 10.1245/s10434018-6639-7 